\title{
Aggressive NK-cell leukemia in a 69 years old Caucasian woman: a case report
}

\author{
Sara Maj Hyldig Matzen ${ }^{1 *}$, Klaus Kallenbach², Anne Regitze Reumert ${ }^{1}$ and Lars Munksgaard ${ }^{3}$
}

\begin{abstract}
Aggressive NK-cell leukemia is a rare malignancy mostly seen in younger Asians with a rapid clinical course and poor prognosis. Here, we describe a 69 years old Caucasian woman presenting with massive leukemization of neoplastic NK-cells. The cells were abnormal in morphology and surface marker expression and this clearly distinguished them from their normal counterpart. They were large and variable in shapes with irregular folding of the nuclei. By flow cytometry, their light scatter characteristics resembled normal monocytes. They showed bright expression of CD56 and CD2 but markedly decreased expression of CD7. They also expressed CD25. The patient presented with general malaise, including high fever, abdominal pain, signs and haemophagocytosis, and she quickly deteriorated and died 11 days after hospitalization. The origin of the leukemic cells of aggressive NK-cell leukemia is most likely the relatively scarce population of CD56 ${ }^{\text {bright }} \mathrm{NK}$-cells, primarily residing lymph nodes and tonsils. The immunophenotype of the case presented here support this, adding CD25 expression which is not earlier addressed in this entity.
\end{abstract}

\section{Background}

The rare aggressive NK-cell leukemia (ANKL) is primarily described in Asian and South American populations (Lima 2013). The disease entity is described in the World Health Organization (WHO) classification for hematopoietic tumors and lymphoid tissues in 2008 but remains poorly characterized as the majority of publications comprise sporadic case reports. This especially holds true for European cases. The course of the disease is rapidly aggravating and nearly always fatal since the neoplastic cells respond poorly to therapy.

Here, we present a case story of an elderly Caucasian woman with an extremely short and aggressive disease course leaving no opportunities of treatment of her leukemia. The case was complicated by rapidly manifestation of serious enterococcus infection and general organ disability impact.

\section{Case description}

A 69-year-old Caucasian female was admitted to the University Hospital, Roskilde, in August 2014, critically

\footnotetext{
*Correspondence: samm@regionsjaelland.dk

${ }^{1}$ Department of Clinical Biochemistry, Copenhagen University Hospital Roskilde, Koegevej 7-13, 4000 Roskilde, Denmark

Full list of author information is available at the end of the article
}

ill with high fever, septicaemi and suspected for acute leukemia. Two weeks earlier her husband reported, the patient admitted her general practitioner because of fever and started up with penicillin on a suspicion of pneumonia. After a few days she admitted the surgical department because of abdominal and lower back pain, and diarrhea. Medical history revealed a prior diagnosis of hypertension treated with two-drug therapy. A smoking history of more than 50 years was noted. Initially, more diagnoses came up and she was transferred to other hospitals twice (suspected for an aorta aneurism and cholecystitis). Initial laboratory assessments showed normal hemoglobin and leukocytes but thrombocytes were $53 \times 10^{9} / \mathrm{L}$ (normal values are $145-390 \times$ $10^{9} / \mathrm{L}$ ). C-reactive protein (CRP) was markedly elevated to $210 \mathrm{mg} / \mathrm{L}$ (normal value $<8 \mathrm{mg} / \mathrm{L}$ ) and Lactate dehydrogenase (LDH) to $1770 \mathrm{U} / \mathrm{L}$ (normal values are 105$205 \mathrm{U} / \mathrm{L}$ ). Leukocyte differential count gave suspicion of a leukemic state or secondary to serious infection. Flow cytometry confirmed a serious leukemic condition, and the patient was transferred to the regional hematological department. On the day of admission, leukocyte count rose above $80 \times 10^{9} / \mathrm{L}$ (normal values are 3,5-8,8 $\times 10^{9} / \mathrm{L}$ ), hemoglobin dropped to $5.4 \mathrm{mmol} / \mathrm{L}$ and need for on-going platelet transfusions to keep thrombocytes

\section{贷 Springer}

(c) 2015 Matzen et al. This article is distributed under the terms of the Creative Commons Attribution 4.0 International License (http://creativecommons.org/licenses/by/4.0/), which permits unrestricted use, distribution, and reproduction in any medium, provided you give appropriate credit to the original author(s) and the source, provide a link to the Creative Commons license, and indicate if changes were made. 
above $20 \times 10^{9} / \mathrm{L}$. Broad-spectrum antibiotics (meropenem) was immediately initiated, numerous blood tests, including blood cultures, viral antibodies and PCR were obtained. Intravenous steroid and rasburicase to prevent tumour lysis syndrome was started. Despite continuous antibiotic and steroid treatment the patients' body temperature fluctuated at feverish level during most of the hospitalization period (see Fig. 1). Previous CT-scan had shown abdominal lymphadenopathy and splenomegali but no enlarged peripheral lymph nodes were visualized. From blood samples a first tentative diagnosis of T-LGL or NK-cell leukemia was made, but further immunophenotypic analyses were necessary to establish the exact diagnosis. Two days later, suddenly, the patients' condition deteriorates and she had to be monitored at the intensive care unit. Creatinine was moderately elevated early in the disease course but now rose steadily along with stop in urine production. She needed assisted ventilation and medicine to maintain adequate blood pressure. The following day, the pathologist suggested a diagnosis of ANKL.

The patients' condition allowed no active treatment for the leukemia other than steroid and supportive care and she died later that day, just 11 days after the admission to hospital. From blood cultures made on the day of demise a gram negative rod, Enterococcus faecium was found and later PCR for Epstein-Barr virus was positive (7200 copies/mL). This allowed a final diagnosis of ANKL as suspected. The patient's blood was tested negative for anti-HIV 1-2, anti-HBc, anti-HCV antibodies, and HBsAg. The clinical picture and blood tests showed signs of haemophagocytosis.

See Fig. 1 for graphical presentation of development in laboratory parameters and Table 1 for an overview of key clinical features.

\section{Morphology}

A few peripheral blood samples were rendered for morphological review. They revealed prominent leukocytosis with approximately $90 \%$ of the nucleated cells showing a polymorphic cell population with variation in size and shape (see Fig. 2a). The nuclei were large with irregular foldings and variably distinct nucleoli (see Fig. $2 b, d-h$ ). The surrounding cytoplasm was lightly basophilic containing dispersed azurophilic granules (see Fig. 2a-b, $\mathrm{d}-\mathrm{h})$. Cytochemical staining of myeloperoxidase was negative in the cell population of interest (data not shown). Immunophenotypic evaluation showed expression of CD3 (see Fig. 2c) while TdT-staining was negative (data not shown).
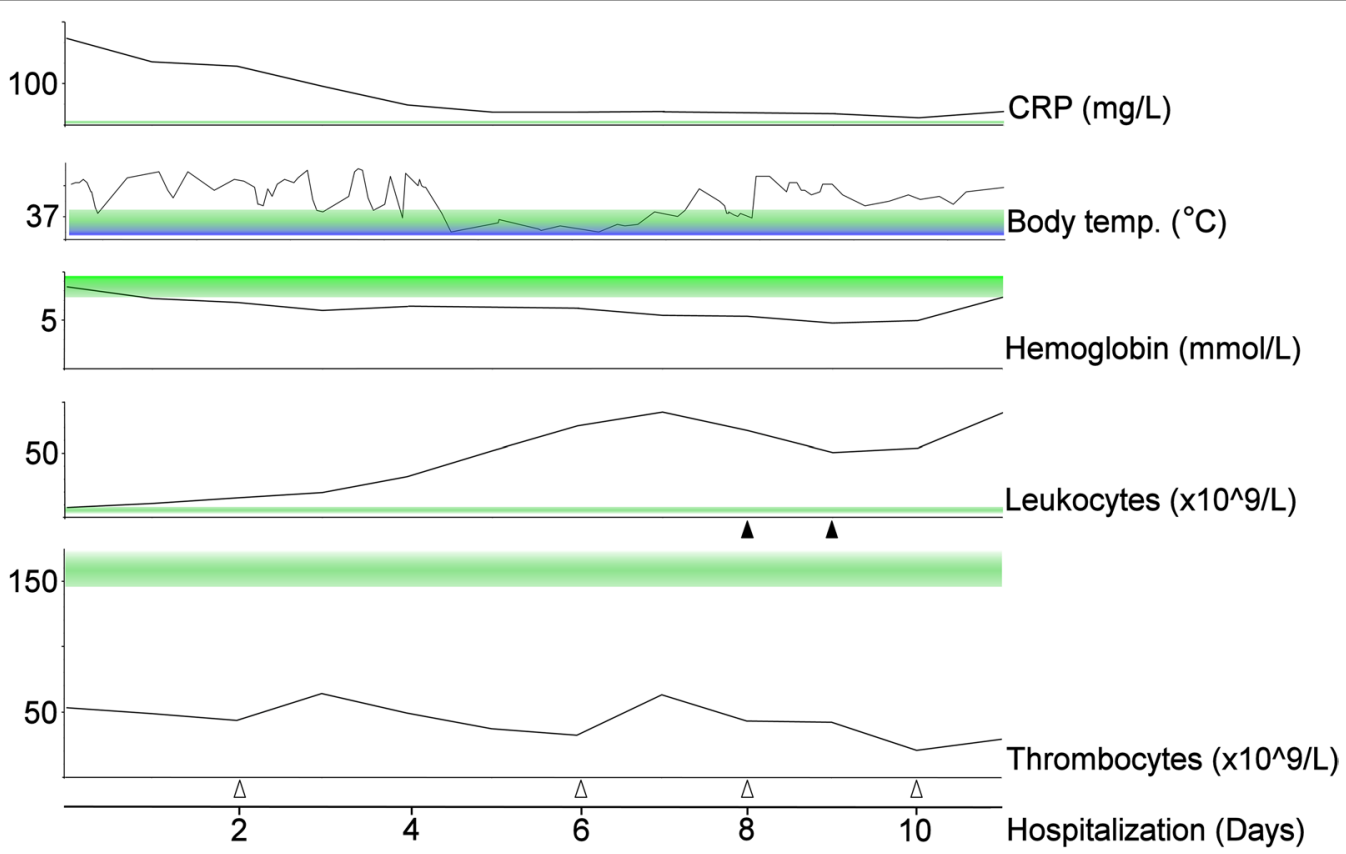

Fig. 1 Laboratory indexes; Graphical presentation of the clinical parameters during the disease course. The CRP value decreased after the 1 st days of treatment with corticosteroids and antibiotics, but it never reached normal level ( $<8 \mathrm{mg} / \mathrm{L})$. Body temperature curve reveals a fluctuating picture that was only briefly and temporarily stabilized at non-feverish level. Haemoglobin was normal at admission but quickly decreased below normal range (7,3-9,5 mmol/L). Leukocyte count was also normal at admission but elevated during the 1st day and the leukocytosis persisted. Thrombocytes were markedly depressed during the entire hospitalization in spite of numerous transfusions, both thrombocyte transfusions (open arrow heads) and whole blood transfusions (closed arrow heads). Green bands indicate normal values for each of the parameters 
Table 1 Clinical data; comparison of clinical features usually presented in patients with ANKL and the clinical features presented in the patient in our case

\begin{tabular}{ll}
\hline & $\begin{array}{l}\text { Classic clinical features } \\
\text { of ANKL,b,c }\end{array}$ \\
\hline $\begin{array}{l}\text { Age (years) } \\
\text { EBV in leukemic cells }\end{array}$ & $30-50$ \\
$\begin{array}{l}\text { Symptoms at admission } \\
\text { of the case patient }\end{array}$ & + \\
$\begin{array}{ll}\text { Fever } \\
\text { Lymphadenopathy }\end{array}$ & + \\
$\begin{array}{l}\text { Splenomegaly } \\
\text { Hepatomegaly }\end{array}$ & + \\
LDH & \pm \\
Thrombocytopeni & + \\
Hemophagocytic syndrome & + \\
\hline
\end{tabular}

\footnotetext{
a (Lima 2013)

b (Lima et al. 2015)

c (Zhang et al. 2014)
}

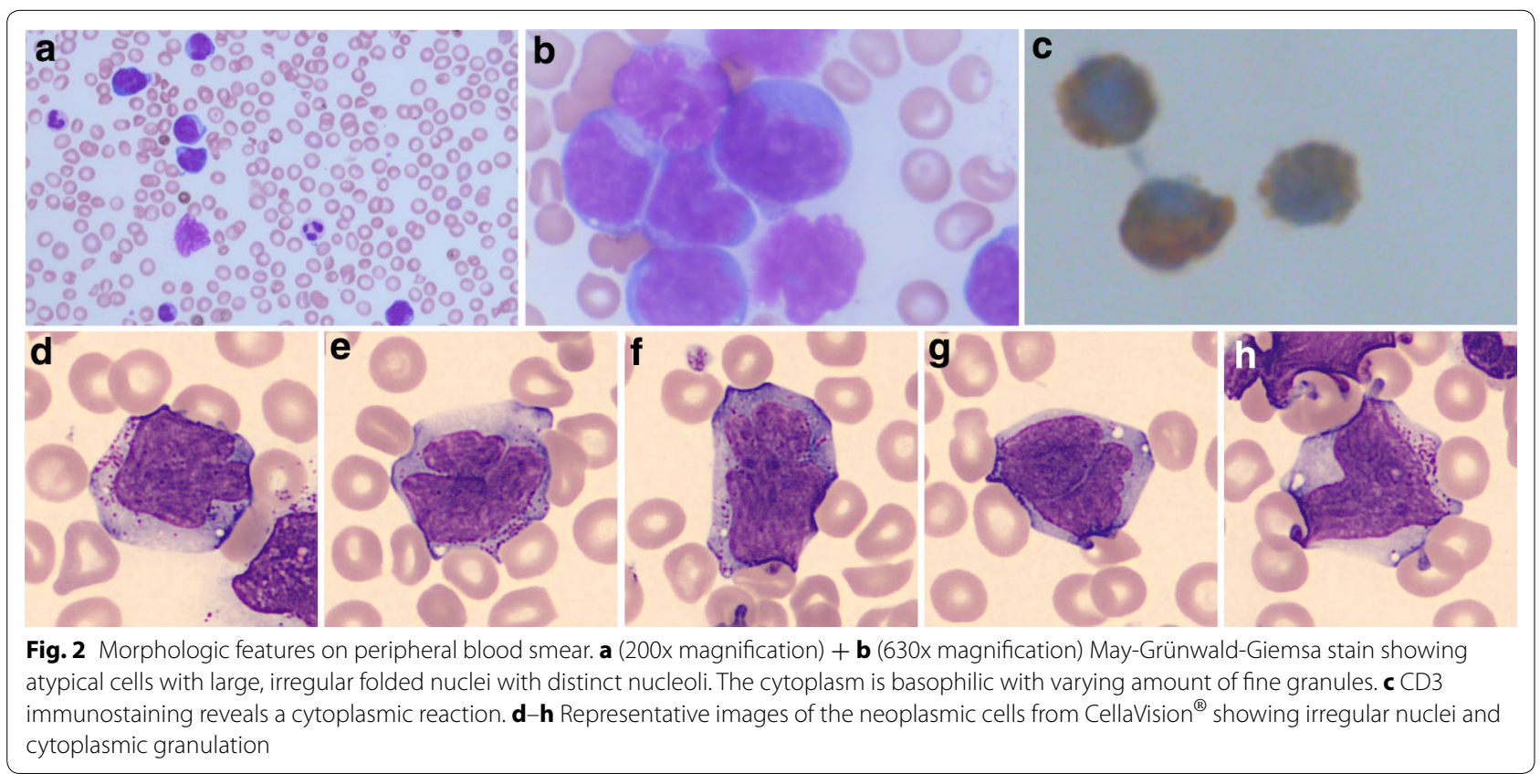

\section{Flow cytometric profile}

A blood sample was sent for flow cytometric analysis. In order to determine the nature of the leukemic cells a wide range of antibodies was applied, of which most turned out negative. This included surface CD3, CD4, and CD8. The light scatter characteristics of the cells resembled that of mature monocytes, e.g. medium side scatter (SSC), high forward scatter (FSC). Bright expression of CD45, CD56 and CD2 lead the suspicion towards NK lineage and the concurrent dim expression of CD7, CD16 and cytoplasmic CD3 $\varepsilon$ consolidated the origin of the leukemia (see Fig. 3). The leukemic cells also expressed
CD25. HLA-DR and CD11b are both reported to be occasionally expressed in this disease entity, but were negative in our case (for complete flowcytometric data, see Additional file 1: Figure S1).

Within the T-cell compartment, we found less than $2 \%$ CD4-neg/CD8-neg, a hallmark of TCR $\gamma \delta$ T-cells. This corresponded to $<0,3 \%$ of the total nucleated cells in the sample.

Molecular analysis of TCR gene rearrangements

Peripheral blood DNA was subjected to molecular PCR-based analyses of TCR gene rearrangements using 

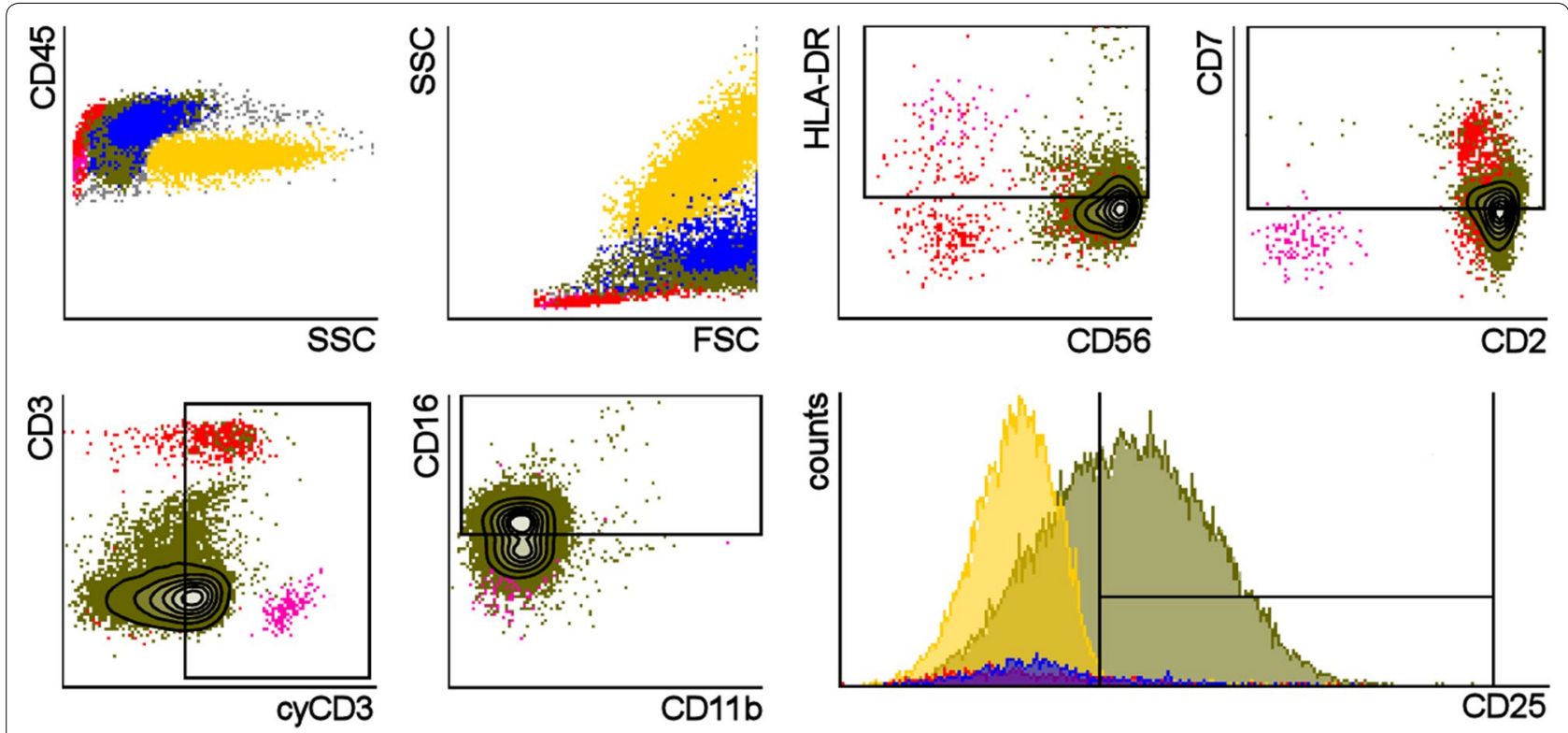

Fig. 3 Flowcytometric data of peripheral blood; Neoplastic NK-cells (green) present in CD45/SSC-plot and in SSC/FSC-plot with characteristics similar to mature monocytes (blue). Red and yellow dots show lymphocytes and granulocytes, respectively. Remaining plots show specific staining for expression of relevant peptide markers. Boxes are placed around the positive portion of cell populations in cases where positive/negative discrimination is not obvious. Only $19 \%$ of the leukemic population was positive for HLA-DR, whereas 42, 51, 52 and $63 \%$ of the same population was positive for CD7, cyCD3, CD16 and CD25, respectively

Biomed2 primers covering TCRgamma (TCRG), TCRbeta (TCRB) and TCRdelta (TCRD) genes. The analysis was performed in replicate. Polyclonal patterns were seen for TCRG and TCRB. Indication of clonal rearrangements was identified in TCRD gene, where two prominent peaks were identified (see Fig. 4). We suspect this to have a technical explanation. TCRD gene is removed when TCR alpha (TCRA) is rearranged and thus, only TCR $\gamma / \delta$ T-cells are certain to harbor rearranged TCRD. Therefore, the TCRD rearrangements will have inherent underrepresentation in a normal T-cell population potentially leading to paucity of TCRD templates for the PCR (Langerak et al. 2012). Since $<0,3 \%$ of the total nucleated cells was assumed to be TCR $\gamma / \delta$ T-cells in this patient, it seems plausible that the clonal peaks identified in the peripheral blood are caused by preferential amplification and should be interpreted as pseudoclonality not associated to the malignant cell population.

\section{Discussion and evaluation}

The recognition of the neoplastic cells was straightforward in the case presented here due to their massive dominance in peripheral blood. However, some patients present with only limited bone marrow or peripheral blood involvement despite heavy disease impact ( $\mathrm{Li}$ et al. 2014). Flow cytometry is already incorporated as a standard screening tool in many hematologic settings. Since the patients at presentation often have symptoms suggestive of acute leukemia, the inclusion of NK-cell markers in the screening panel for acute leukemia would enable the detection of abnormal NK-cells even in cases with minimal infiltration. The increased size and granulation compared to normal peripheral NK cells places them in the monocyte gate when using CD45, SSC and FSC as segregation parameters. CD56 expression on monocytes is a well-known aberrancy in several diseases and is also seen on a small percentage of normal monocytes (Krasselt et al. 2013). Thus repudiating monocytic nature of the abnormal cells is prerequisite for recognition of the population. This could be done by including CD14 or CD64 in combination with CD56 in the screening panel.

Generally, NK cells are subdivided into two subpopulations based on their expression of CD56 and CD16. The CD $56^{\text {bright }} / \mathrm{CD} 16^{\text {neg/dim }}$ is normally a minority in peripheral blood but dominates in tonsils, lymph nodes and in deciduas during early pregnancy (Poli et al. 2009; Tao et al. 2015). They have limited cytotoxic capacity, but have been shown to be highly cytotoxic towards activated T-cells in comparison with the CD56 ${ }^{\text {dim }}$ subset (Bielekova et al. 2006). It is hypothesized that neoplastic NK cells of ANKL represent a transformed counterpart of the CD56 ${ }^{\text {bright }}$ subset (Lima et al. 2015). Since nearly all ANKL cases present with EBV DNA in the leukemic cells, it is tempting to assume that this transformation is 


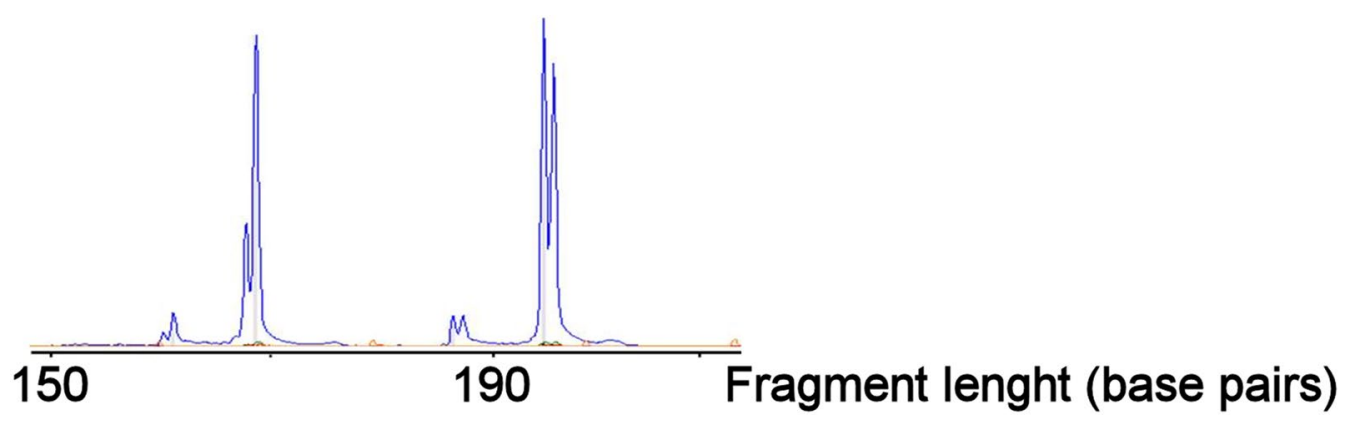

Fig. 4 Molecular analysis of TCRdelta gene rearrangements in peripheral blood; Two prominent peaks are identified in fragment sizes 169 base pairs and 196 base pairs, respectively. The double-peak appearance is caused by DNA polymerase-catalyzed addition of nontemplated extra nucleotides

initiated by the EBV infection. Supportive of the hypothesis is the fact that NK cells in lymph nodes have been identified as targets during early Epstein Barr virus infection (Trempat et al. 2002). A study of the immunophenotype of 29 de novo ANKL revealed bright expression of CD56 accompanied by lack of CD5- and CD57-ekspression as the only consistent pattern (Li et al. 2014). CD57 is only expressed in the normal CD56 $6^{\mathrm{dim}}$ compartment, supporting the theory of $\mathrm{CD} 56^{\text {bright }}$ subset as the cell of origin in ANKL. However, more extensive subdivision of normal NK cells might be relevant. Fu, Tian and Wei suggest a fractioning of the CD56 $6^{\text {bright }}$ subset into $\mathrm{NK}^{\text {regulatory }}$ and $\mathrm{NK}^{\text {tolerant }}$ by their expression or lack of $\mathrm{CD} 27$, respectively. The $\mathrm{CD}^{2} 7^{+}$regulatory NK cells are described as abundant cytokine producers (Fu et al. 2014). Uncontrolled cytokine production, often leading to hemophagocytic lymphohistiocytosis, is reported in many cases of ANKL (Akashi and Mizuno 2000). On that basis it is intriguing to suggest the $\mathrm{NK}^{\text {regulatory }}$ as probable cellular origin of ANKL. The endogenous immune evasive potential of a cell type naturally involved in modulation of immune response would provide supportive growth conditions for the malignant clone. However, to the best of our knowledge CD27-expression in ANKL has not been investigated and thus, the exact origin cannot be designated within the CD56 $6^{\text {bright }}$ populations. It should be emphasized that the CD56 $6^{\text {bright }}$ NK cells only recently gained wider investigational focus and that their biology and functions by no means are fully drawn up $(\mathrm{Fu}$ et al. 2014).

The majority of normal PB NK-cells are negative for CD25-expression and the same is true for NK-cells of Chronic NK-cell lymphoproliferative disorder (CLPDNK) (Lima et al. 2004). To our knowledge, the marker has not been addressed in specific reports of ANKL. In a series-report of 12 patients with either ANKL or extranodal NK/T-cell lymphoma, nasal type (NKTCL) it was reported that 6 unspecified cases were tested negative for CD25 (Lima et al. 2015). In contrast, Yu and colleages found the marker consequently positive in a report on immunophenotype for NKTCL (Yu et al. 2014). Here, we report positive staining of the marker by flow cytometry with $63 \%$ of the neoplastic cells showing a brighter signal than the negative granulocytes (see Fig. 3). CD25 expression is previously shown to be an indication of high proliferation potential in human NK-cells (Clausen et al. 2003). It is a key component of the high affinity heterotrimeric receptor for IL-2, a cytokine well-known for its properties in NK proliferation and enhancement of cytokine production (Bielekova et al. 2006). CD25expression has been shown for decidual CD56 ${ }^{\text {bright }} \mathrm{NK}$ cells (Tao et al. 2015). It has also been shown that previously activated NK-cells are able to remember the activation and persist in the host with enhanced functional capacity. The authors designated this cell type cytokine induced memory-like (CIML) NK cells and hypothesize that the increased CD25 expression seen in these cells are at least partly responsible for their preferential expansion and reactivation in response to low dose IL2 [reviewed by (Romee et al. 2014)]. So far, one can only speculate to what extent the CD25 expression influence the course of the disease in ANKL, but it seems likely that its role is exacerbating.

The hemophagocytic syndrome is often seen in this patient group due to massive activation of monocytes and macrophages by cytokines released from the neoplastic cells (Zhang et al. 2014; Maakaroun et al. 2010). The syndrome was also seen in our case.

\section{Conclusions}

ANKL remains a challenging disease to diagnose owing to the fast development, rare nature and varying presentation. However, as reported previously, the leukemic cells in this case showed aberrant expression of 
several cell markers. It has been suggested that immunohistochemistry and EBV-encoded small RNAs (EBER) detection in a bone marrow biopsy provide a reliable diagnostic approach (Soliman et al. 2014). However, as also reported by others, a bone marrow sample might not be easily obtained, and in addition, the bone marrow samples are rarely the first material to reach the paraclinical laboratories. A bone marrow sample was never taken from the patient presented here due to the very rapid deterioration of her condition. The diagnosis was instead made on blood samples in which the leukemic cells were sufficiently represented. To this aim, the flow cytometric profile was of great assistance to the initial morphological assessment. The potential to stain multiple proteins within a few hours makes the technique a valuable alternative to immunohistochemistry in cases were a complicated diagnosis is needed in very short time. Cell type specific markers provided certainty of the cell of origin in a morphologically difficult leukemia.

\section{Additional file}

Additional file 1: Figure S1. Complete flow cytometric data. Histograms of all marker expression evaluated by flow cytometry. Some markers were evaluated multiple times in different antibody mixes using the same or different fluorochromes. In these cases, only one plot is depicted here. All major cell populations are shown in relative sizes as follows: neoplastic NK-cells in olive green, normal lymphocytes in red, granulocytes in yellow and monocytes in blue.

\section{Abbreviations}

ANKL: aggressive natural killer cell leukemia; EBV: Ebstein Barr virus; EBER: EBV-encoded small RNAs; TCR: T cell receptor; SSC: side scatter; FSC: forward scatter; LDH: lactate dehydrogenase; CRP: C-reactive protein; HIV: human immunodeficiency virus; Anti-HBc: hepatitis B virus C-antibody; HBsAg: hepatitis $B$ virus s-antigen; $H C V$ : human cytomegalovirus.

\section{Authors' contributions}

SMHM took part in the flow cytometric analysis of the patient sample and drafted the manuscript. KK participated in the pathological examination of the patient samples and wrote the morphological description. ARR participated in the evaluation of patient samples analyzed by Cellavision. LM was involved in the treatment and final diagnosis of the patient and wrote the clinical part of the manuscript. All authors read and approved the final manuscript.

\section{Author details}

${ }^{1}$ Department of Clinical Biochemistry, Copenhagen University Hospital Roskilde, Koegevej 7-13, 4000 Roskilde, Denmark. ${ }^{2}$ Department of Clinical Pathology, Copenhagen University Hospital Roskilde, Koegevej 7-13, 4000 Roskilde, Denmark. ${ }^{3}$ Department of Hematology, Copenhagen University Hospital Roskilde, Koegevej 7-13, 4000 Roskilde, Denmark.

\section{Competing interests}

The authors declare that they have no competing interests.

\section{Consent for publication}

The study was approved by the Danish Data Protection Agency (J. No. 201541-4237). Furthermore, the patient's son has consented to the use of the patient's medical and personal information in this case report.

Received: 28 August 2015 Accepted: 24 November 2015

Published online: 09 December 2015

\section{References}

Akashi K, Mizuno S (2000) Epstein-Barr virus-infected natural killer cell leukemia. Leuk Lymphoma 40:57-66

Bielekova B, Catalfamo M, Reichert-Scrivner S, Packer A, Cerna M, Waldmann TA, McFarland H, Henkart PA, Martin R (2006) Regulatory CD56(bright) natural killer cells mediate immunomodulatory effects of IL-2Ralphatargeted therapy (daclizumab) in multiple sclerosis. Proc Natl Acad Sci USA 103:5941-5946

Clausen J, Vergeiner B, Enk M, Petzer AL, Gastl G, Gunsilius E (2003) Functional significance of the activation-associated receptors CD25 and CD69 on human NK-cells and NK-like T-cells. Immunobiology 207:85-93

Fu B, Tian Z, Wei H (2014) Subsets of human natural killer cells and their regulatory effects. Immunology 141:483-489

Krasselt M, Baerwald C, Wagner U, Rossol M (2013) CD56 + monocytes have a dysregulated cytokine response to lipopolysaccharide and accumulate in rheumatoid arthritis and immunosenescence. Arthritis Res Ther 15:R139

Langerak AW, Groenen PJ, Bruggemann M, Beldjord K, Bellan C, Bonello L, Boone E, Carter Gl, Catherwood M, Davi F, Delfau-Larue MH, Diss T, Evans PA, Gameiro P, Garcia SR, Gonzalez D, Grand D, Hakansson A, Hummel M, Liu H, Lombardia L, Macintyre EA, Milner BJ, Montes-Moreno S, Schuuring E, Spaargaren M, Hodges E, van Dongen JJ (2012) EuroClonality/ BIOMED-2 guidelines for interpretation and reporting of $\mathrm{Ig} / \mathrm{TCR}$ clonality testing in suspected lymphoproliferations. Leukemia 26:2159-2171

Li C, Tian Y, Wang J, Zhu L, Huang L, Wang N, Xu D, Cao Y, Li J, Zhou J (2014) Abnormal immunophenotype provides a key diagnostic marker: a report of 29 cases of de novo aggressive natural killer cell leukemia. Transl Res 163:565-577

Lima M (2013) Aggressive mature natural killer cell neoplasms: from epidemiology to diagnosis. Orphanet J Rare Dis 8:95

Lima M, Almeida J, Montero AG, Teixeira MA, Queiros ML, Santos AH, Balanzategui A, Estevinho A, Alguero MC, Barcena P, Fonseca S, Amorim ML, Cabeda JM, Pinho L, Gonzalez M, San MJ, Justica B, Orfao A (2004) Clinicobiological, immunophenotypic, and molecular characteristics of monoclonal CD56 ×dim chronic natural killer cell large granular lymphocytosis. Am J Pathol 165:1117-1127

Lima M, Spinola A, Fonseca S, Santos AH, Rodrigues J, Oliveira L, Queiros ML, Santos M, Goncalves M, Lau C, Teixeira MA, Goncalves C, Marques C, Guerreiro M, Cunha M, Principe F, Coutinho J (2015) Aggressive mature natural killer cell neoplasms: report on a series of 12 European patients with emphasis on flow cytometry based immunophenotype and DNA content of neoplastic natural killer cells. Leuk Lymphoma 56:103-112

Maakaroun NR, Moanna A, Jacob JT, Albrecht H (2010) Viral infections associated with haemophagocytic syndrome. Rev Med Virol 20:93-105

Poli A, Michel T, Theresine M, Andres E, Hentges F, Zimmer J (2009) CD56bright natural killer (NK) cells: an important NK cell subset. Immunology 126:458-465

Romee R, Leong JW, Fehniger TA (2014) Utilizing cytokines to function-enable human NK cells for the immunotherapy of cancer. Scientifica (Cairo) 2014:205796

Soliman DS, Sabbagh AA, Omri HE, Ibrahim FA, Amer AM, Otazu IB (2014) Rare aggressive natural killer cell leukemia presented with bone marrow fibrosis - a diagnostic challenge. Springerplus 3:390

Tao Y, Li YH, Piao HL, Zhou WJ, Zhang D, Fu Q, Wang SC, Li DJ, Du MR (2015) CD56(bright)CD25+ NK cells are preferentially recruited to the maternal/ fetal interface in early human pregnancy. Cell Mol Immunol 12:77-86

Trempat P, Tabiasco J, Andre P, Faumont N, Meggetto F, Delsol G, Gascoyne RD, Fournie JJ, Vivier E, Brousset P (2002) Evidence for early infection of nonneoplastic natural killer cells by Epstein-Barr virus. J Virol 76:11139-11142

Yu JB, Zuo Z, Zhang WY, Yang QP, Zhang YC, Tang Y, Zhao S, Mo XM, Liu WP (2014) Identification of immunophenotypic subtypes with different prognoses in extranodal natural killer/T-cell lymphoma, nasal type. Hum Pathol 45:2255-2262

Zhang Q, Jing W, Ouyang J, Zeng H, George SK, Liu Z (2014) Six cases of aggressive natural killer-cell leukemia in a Chinese population. Int J Clin Exp Pathol 7:3423-3431 